\title{
Accuracy of Distance Recordings in Eight Positioning-Enabled Sport Watches: Instrument Validation Study
}

Rahel Gilgen-Ammann, PhD; Theresa Schweizer, BSc; Thomas Wyss, PhD

Swiss Federal Institute of Sport Magglingen, Magglingen/Macolin, Switzerland

Corresponding Author:

Rahel Gilgen-Ammann, $\mathrm{PhD}$

Swiss Federal Institute of Sport Magglingen

Hauptstrasse 247

Magglingen/Macolin,

Switzerland

Phone: 41584676321

Email: rahel.gilgen@baspo.admin.ch

\section{Abstract}

Background: Elite athletes and recreational runners rely on the accuracy of global navigation satellite system (GNSS)-enabled sport watches to monitor and regulate training activities. However, there is a lack of scientific evidence regarding the accuracy of such sport watches.

Objective: The aim was to investigate the accuracy of the recorded distances obtained by eight commercially available sport watches by Apple, Coros, Garmin, Polar, and Suunto when assessed in different areas and at different speeds. Furthermore, potential parameters that affect the measurement quality were evaluated.

Methods: Altogether, $3 \times 12$ measurements in urban, forest, and track and field areas were obtained while walking, running, and cycling under various outdoor conditions.

Results: The selected reference distances ranged from $404.0 \mathrm{~m}$ to $4296.9 \mathrm{~m}$. For all the measurement areas combined, the recorded systematic errors ( \pm limits of agreements) ranged between $3.7( \pm 195.6) \mathrm{m}$ and $-101.0( \pm 231.3) \mathrm{m}$, and the mean absolute percentage errors ranged from $3.2 \%$ to $6.1 \%$. Only the GNSS receivers from Polar showed overall errors $<5 \%$. Generally, the recorded distances were significantly underestimated (all $P$ values <.04) and less accurate in the urban and forest areas, whereas they were overestimated but with good accuracy in $75 \%(6 / 8)$ of the sport watches in the track and field area. Furthermore, the data assessed during running showed significantly higher error rates in most devices compared with the walking and cycling activities.

Conclusions: The recorded distances might be underestimated by up to $9 \%$. However, the use of all investigated sport watches can be recommended, especially for distance recordings in open areas.

(JMIR Mhealth Uhealth 2020;8(6):e17118) doi: $\underline{10.2196 / 17118}$

\section{KEYWORDS}

geographic information systems; GPS measurement error; sports; geographic locations; monitoring physical training; movement analysis

\section{Introduction}

\section{Background}

There are many wearable devices on the market, especially in the health and sports sectors, that can access global navigation satellite system (GNSS) information [1]. A world survey of fitness trends identified wearable technologies such as GNSS-enabled watches and activity trackers as a key trend in 2016, 2017, and 2019 [2]. Conventional GNSS-enabled sport watches are predominant for a diverse population of active runners of different fitness levels [3,4]. For example, the wearable technologies used by runners during a half-marathon and marathon competition were as follows: $44.7 \%$ (437/977) were represented by GNSS-enabled sport watches and $18.5 \%$ (181/977) by mobile phones with a combined app to track running performance. In comparison, the proportions of heart rate monitors $(37 / 977,3.8 \%)$, wristband activity trackers (27/977, 2.8\%), and smart watches $(14 / 977,1.4 \%)$ were quite low during these competitions. Wiesner et al [4] revealed that within runners using wearable technologies, the most frequent parameters of interest were the distance covered (523/617, 
$84.8 \%)$, time $(441 / 617,71.5 \%)$, and average speed $(412 / 617$, $66.8 \%$ ). In that study, 3 out of 4 participants stated that they always trusted the data. As the users rely on these data to guide their training or competition, monitor their training volume, or plan their exercises, knowledge about GNSS accuracy is of importance [5].

\section{Prior Work}

In a systematic review of mobile apps to quantify aspects of physical activity, $20 \%(5 / 25)$ of the studies investigated the validity of mobile apps when measuring distance using GNSS information [6]. Mean percentage errors ranged between $2 \%$ and $10 \%$. A systematic review of the validity of consumer-wearable activity trackers in 2015 revealed 22 studies [7]. However, only one study reported information on recorded distance but not using GNSS information. Recently, Pobiruchin and coworkers [3] investigated the recorded distance data obtained from different GNSS-enabled devices and brands during a half-marathon competition. They revealed small mean absolute errors of $0.12 \mathrm{~km}(0.6 \%)$ during the $21.1 \mathrm{~km}$ course. In the only study investigating GNSS-enabled sport watches, results from the validity of the recorded distances showed $0.8 \%$, $1.2 \%$, and $6.2 \%$ error rates on a straight path with open sky, an urban path, and a forest path, respectively [5]. However, further investigations are needed on recorded distances obtained in standardized settings to learn about different brands and products in the sport sector. Different sport watches should be investigated simultaneously in various real-world scenarios, both area-wise and speed-wise [8-10].

\section{Difficulties in the Global Navigation Satellite System}

To better understand why there might be difficulties in the accurate assessment of distance traveled by GNSS-enabled devices, one must comprehend how such devices work and what the GNSS signal affects, and therefore, how this impacts the measurement quality. Four main satellite implementations exist: GPS (United States), Global Navigation Satellite System (GLONASS, Russia), Galileo (European Union), and BeiDou (China). The number of satellites for GPS, GLONASS, Galileo, and BeiDou are 31, 27, 22, and 19, respectively, which circle the Earth twice a day in a precise orbit at an altitude of approximately 20,000 km [11-15]. Each satellite transmits a unique right-hand polarized signal and orbital parameters that allow GNSS-enabled devices to decode and compute the precise location of the satellite. The GNSS receiver measures the distance to each satellite by the amount of time it takes to receive a transmitted signal to exactly locate the user's position on Earth [15]. Several factors affect the signal transmitted between the satellites and the GNSS receiver such as bad signal acquisition, number of satellites, signal multipath, satellite geometry, and GNSS receiver clock errors [1,15-17]. Bad signal acquisition can happen if the user of a GNSS-enabled device disregards any of the manufacturers' main instructions to achieve a high GNSS signal: staying outside, regularly synchronizing the watch to the mobile app or computer to download the latest satellite data (= assisted GPS data), updating the watch's GNSS setting for whatever activity, or choosing GPS + GLONASS or Galileo. The more satellites a GNSS receiver can detect, the better the accuracy. To calculate one's 2D position (latitude and longitude), a GNSS receiver must be locked on to the signal of at least three satellites. Therefore, the user should remain stationary with the watch facing up during signal acquisition. Furthermore, the signal multipath and satellite geometry affect the transmitted signal. A user may get position errors or no position readings at all when a signal is blocked. This can occur because a GNSS signal does not penetrate any solid constructions or water. In addition, the GNSS signal is reduced by dense vegetation or cloudy weather or near objects and buildings, as there are reflections that transform the right-hand polarization into left-hand polarization before it reaches the GNSS receiver. Generally, the satellite signals are more effective when the satellites are located at wide angles relative to one another. Therefore, during signal acquisition, the user should stay away from large buildings and dense vegetation and, ideally, remain in a flat open area. Last, measurement quality can be hampered by timing errors the GNSS receiver might have because it is less accurate than the atomic clocks on GNSS satellites. The user, however, cannot change the clock errors in the GNSS receiver. In the northern hemisphere, the ground stations' determined locations can vary due to the mentioned error sources. With GPS, GLONASS, and GPS + GLONASS, the determined horizontal (and vertical) location errors can be 8.0 (SD 17.1) m, 9.4 (SD 18.3) m, and 7.1 (SD 14.0) m, respectively, with a $95 \%$ confidence interval [18-20]. Overall, little to no information about positioning accuracy is provided by the most common manufacturers of GNSS-enabled sport watches. Scott et al [21] rated measures of validity of GPS in team sports as good $(<5 \%)$, moderate $(5 \%$ to $10 \%)$, or poor $(>10 \%)$.

\section{Aims of the Study}

The aim was to investigate the accuracy of and parameters affecting the recorded distances obtained by eight sport watches from Apple, Coros, Garmin, Polar, and Suunto when assessed in different areas and at different speeds under different external circumstances.

\section{Methods}

\section{Study Setting}

In this instrument validation study, measurements were conducted in three areas while performing three different speed categories [10] (Figure 1):

- Urban area: in the city center of Biel/Bienne (Switzerland) at $434 \mathrm{~m}$ above sea level on a flat street with narrow and partly high buildings

- Forest area: in terrain in Magglingen (Switzerland) at 905 $\mathrm{m}$ above sea level on uphill (total gradient of 52 altitude meters and $11 \%$ slope), downhill, and flat paths with partly tall trees

- $\quad$ Track and field area: in an open track and field stadium in Magglingen without a tribune at $954 \mathrm{~m}$ above sea level on a $400 \mathrm{~m}$ track in the middle of lane 1 without any satellite visibility constraints 
Figure 1. The urban (1), forest (2), and track and field (3) measurement areas. White circles divide the courses into subsections that were randomly combined and added up to result in different selected reference distances within the same setting.
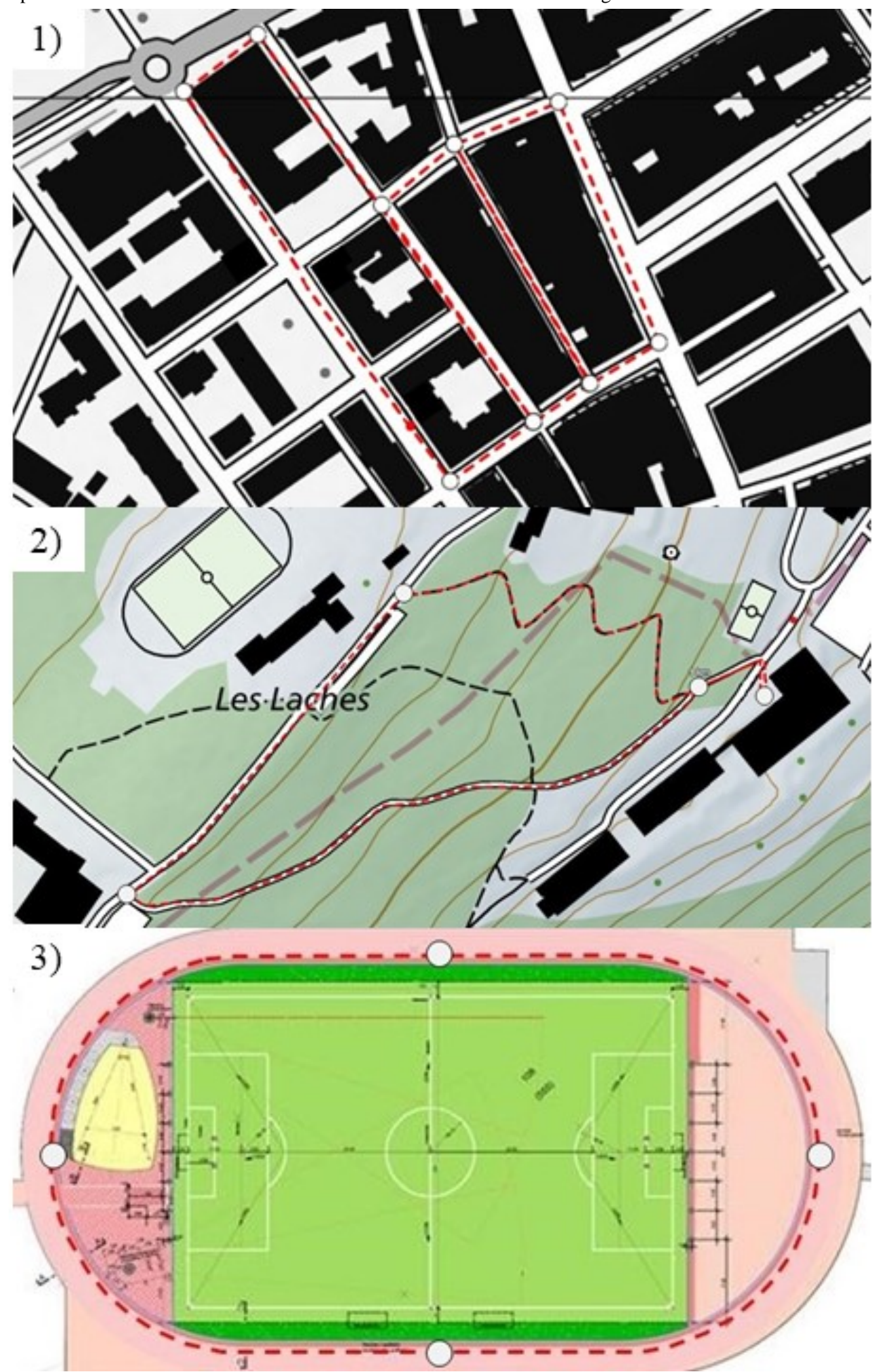

The courses in each area were marked to allow ideal replications of the measurements. All courses in a respective area were split into subsections that were randomly combined within one measurement area resulting in selected reference distances of $400 \mathrm{~m}$ to $4500 \mathrm{~m}$. This was chosen to ensure variance of traveled distances as a possible independent variable within the same controlled setting and investigate whether the distance per se and number of travel direction changes affected the results.
Subsections of each course were accomplished partly or entirely or repeated in either direction (including U-turns), or any combination of these (Figure 1). A trundle wheel [22] was used as the reference measure for all selected subsections. Each subsection was assessed twice with the trundle wheel with an accuracy to $1 \mathrm{~cm}$.

Measurements were taken in the three speed categories-walking, running, and cycling-to represent low-, 
moderate-, and high-gait speeds [1]. These three speed categories were self-paced by the subject but steady — according to the subjective feeling - within one measurement. The cycling was performed using an electric bike (e-bike) [23] to ensure high speeds and steady and straight riding, particularly on the uphill section in the forest area. Self-pacing and different subsections were chosen to ensure data acquisition that represented different real-life situations. The activity task itself and steady speed were secondary, as the primary aim was to validate recorded distances. Also, having a range of reference distances allowed statistical analyses with normally distributed data.

\section{Instruments}

Eight watches from the most common manufacturers in the field of sport watches (as of January 2019) were included in this study. The specific types were chosen based on personal communications with exercise physiologists and endurance athletes (see Table 1). All units were configured to the lowest possible 1-second (1 Hertz) GNSS recording, and the GPS + GLONASS satellite system was selected except for the Apple Watch Series 4 (Apple Inc), which does not have the option to choose the satellite system, and the V800 (Polar Electro Oy), which only has GPS due to its antenna implementation.

Table 1. Investigated sport watches and their specifications.

\begin{tabular}{lllll}
\hline Sport watch model & Abbreviation & Manufacturer & Serial number & Firmware or OS version \\
\hline Apple Watch Series 4 & AW4 & Apple Inc & FH7XD28MKDH9 & 5.2 \\
Apex 46 mm & CoA & Coros Wearables Inc & 73 F855 & 1.31 \\
Fenix 5X Plus & G5X+ & Garmin Ltd & 5 MM005560 & $6.0(7.6)^{\mathrm{a}}$ \\
Forerunner 935 & GF935 & Garmin Ltd & 50 S007800 & $12.50(13.00)^{\mathrm{a}}$ \\
Vantage M & VM & Polar Electro Oy & 464F832E & 4.0 .0 \\
Vantage V & VV & Polar Electro Oy & 4AF6F824 & 4.0 .0 \\
V800 & V800 & Polar Electro Oy & 306AE719 & 1.11 .49 \\
Suunto 9 Baro & S9B & Suunto Oy & 1.8251E+11 & $2.5 .18(2.6 .54)^{\mathrm{a}}$ \\
\hline
\end{tabular}

${ }^{\mathrm{a}}$ Updates were needed during data collection to synchronize data to the respective website. Firmware version is listed after the update.

\section{Subject}

One healthy, fit, and lean person (female, aged 26 years, 53.0 $\mathrm{kg}, 1.58 \mathrm{~m}$ ) performed all measurements. Having one subject ensured perfect standardized measurements. Moreover, independent variables such as body height, arm length and movement, walking pattern, etc, could be precluded. The subject was well familiar with the handling of all eight investigated watches and with the study design.

\section{Data Collection}

Measurements were scheduled for different days (7:00 am to 6:00 pm) from April to July 2019. On measurement days, all sport watches were synchronized to the respective mobile app and computer software by the supervisor to download the latest satellite data.

During each measurement, four watches were worn simultaneously. The subject wore two watches per forearm at least $4 \mathrm{~cm}$ apart to minimize potential interference between the devices (Figure 2). The combination of which four watches, the wearing side (wearing the watches on the right or left arm), and the wearing position (wearing the watch higher or lower on the forearm) were randomly assigned by the supervisor using a covariate adaptive randomization approach prior to the measurements $[10,24]$. It is worth noticing that the higher the watch is located on the arm, the stronger the signal-blocking effect due to the body's interference. The watches were always mounted on bare skin and were not covered by sleeves. The subject prepared all the watches to receive the GNSS signal while standing in a flat, mostly open area without large buildings or dense vegetation. After readying each watch's positioning connection, the subject waited another 5 minutes with arms outstretched, watches facing up, for calibration purposes to reach the best GNSS signal quality prior to starting the data acquisition (Figure 2).

Thereafter, the subject started the watches from left to right and did the same to stop the measurement. As the data collection was performed with one subject but eight watches, the same measurement-speed category and area with its combination of course subsections to reach the same reference distance lengths - was accomplished twice in a row, each time with four watches. Additionally, the following parameters were protocolled by the supervisor for each assessment: course turns per $1000 \mathrm{~m}$, time of day, temperature, precipitation, sun, humidity, solar irradiance, and wind velocity [10]. In total, each of the three areas was completed four times in each of the three speed categories, resulting in $3 \times 4 \times 3=36$ measurements. 
Figure 2. Randomly assigned wearing position on the forearm of the sport watches during one measurement (left). Calibration posture with arms outstretched to achieve the best global navigation satellite signal quality (right).

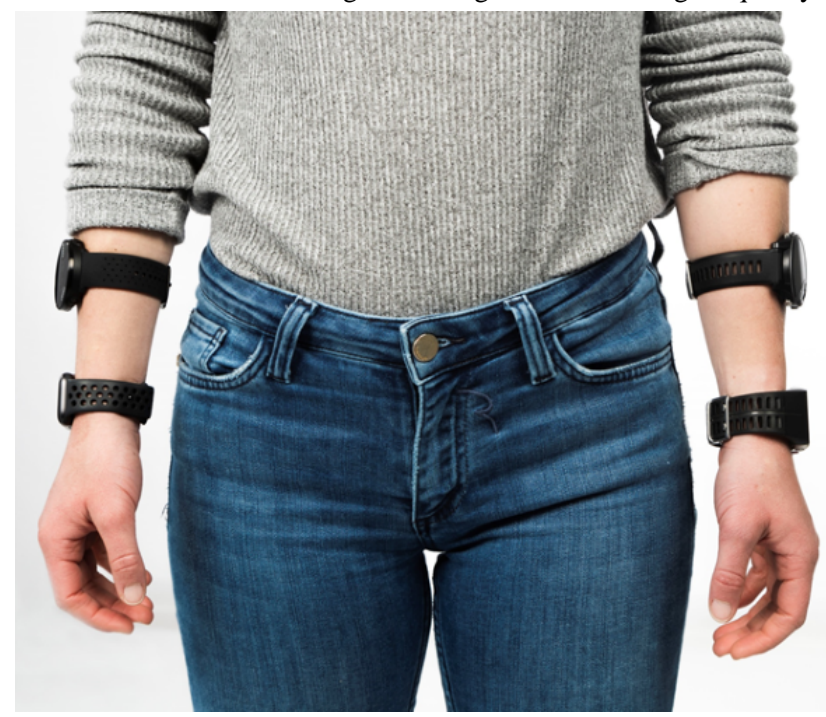

\section{Data Processing}

After each measurement, the data were uploaded to the respective software provided by and exported as default by the five investigated manufacturers. In the Garmin and Suunto devices, a firmware update was required during data collection to synchronize the data to the respective website. These data were not treated differently. To calculate the recorded distances of each watch, only the values of the real measurement time period were computed, except the data from the AW4, which could not be exported. In this case, the distance values shown on the AW4 display were noted, entered, and double checked in an Excel Windows 2016 (Microsoft Corporation) file by the supervisor for each measurement.

\section{Statistical Analysis}

Descriptive statistics with mean absolute and percentage errors, dependent samples 2-tailed $t$ tests, Bland-Altman analyses, and a $\pm 5 \%$ accuracy of the recorded distance were used. The dependent $t$ test was applied to test whether the difference of the recorded distances between tested devices and the reference values was zero. Bland-Altman analyses with corresponding 95\% limits of agreement (SD 1.96) were used to calculate systematic errors in the recorded distances. The $\pm 5 \%$ accuracy of the recorded distances was defined as the percentage at which the respective watch recording was within the proposed equivalence zone of $\pm 5 \%$ from the reference values $[21,25]$. Furthermore, multivariate linear regression analyses with stepwise backward elimination were used for each watch to detect independent variables with significant influence on the mean absolute error (MAE). The independent predictor variables investigated were speed categories, area, time of day, temperature, turns per $1000 \mathrm{~m}$, precipitation, sun, humidity, solar irradiance, wind velocity, watch wearing side $(0=$ right arm; $1=$ left arm), and watch-wearing position ( $0=$ higher; $1=$ lower on the forearm). These were chosen as potential

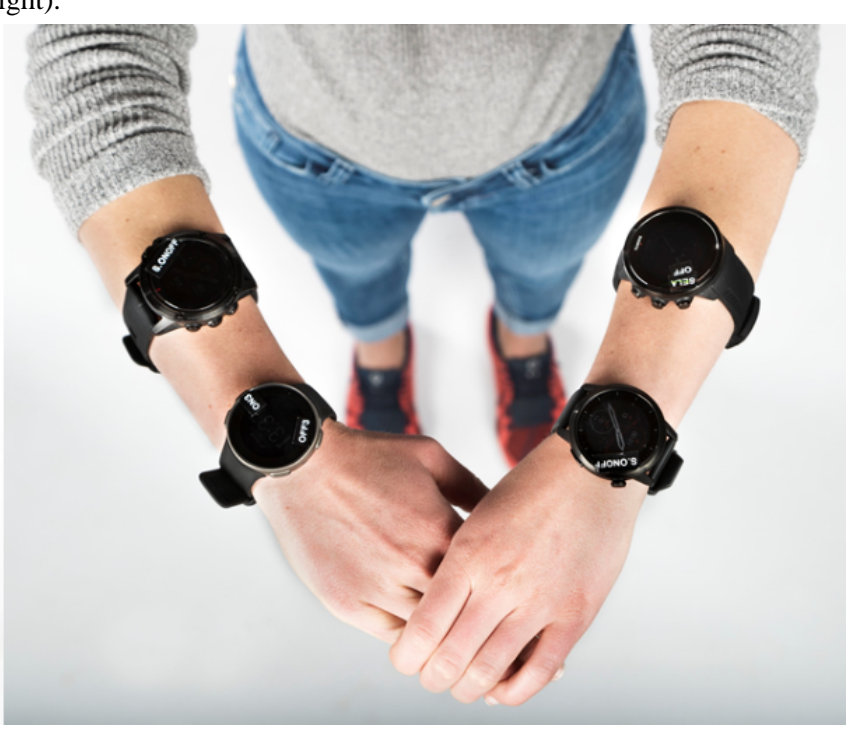

predictors, as they occur during a user's everyday life (where to move, at what pace, how curvy the terrain is, etc); the wearing position on the higher and lower forearm was included to demonstrate whether the setup in the study affected the result. The adjusted $R^{2}$ and $\beta^{2}$ were used to estimate the explained variances of the dependent variable by all the included variables and by each independent variable, respectively. In the case of multicollinearity $(r \geq 80)$ or the nonsignificant prediction of the MAE, the relevant variable was excluded from the regression analysis. Any $P<.05$ was considered statistically significant, and the $\alpha$ level was .05. The statistical analyses were applied using SPSS Statistics 25.0 (IBM Corporation) and Excel.

\section{Results}

\section{Main Findings}

In total, $100 \%(36 / 36)$ of the measurements were recorded for each sport watch but in the S9B, 97\% (35/36) of the measurements were analyzed due to a technical failure during one assessment in the forest area. The walking, running, and biking was accomplished on average at 5.4 (SD 0.2), 10.2 (SD 0.7 ), and 17.6 (SD 2.6) $\mathrm{km} / \mathrm{h}$, respectively.

For all three measurement areas combined, the recorded systematic errors (limits of agreements) ranged between 3.7 $( \pm 195.6) \mathrm{m}$ and $-101.0( \pm 231.3) \mathrm{m}$ for the V800 and CoA, respectively (Multimedia Appendix 1). The mean absolute percentage error (MAPE) ranged from $3.2 \%$ to $6.1 \%$ for the V800 and the S9B, respectively. Only the three GNSS receivers from Polar showed overall MAPEs $<5 \%$. On average, the mean recorded distances within $\pm 5 \%$, when compared with the reference values, ranged from $80.6 \%(29 / 36)$ in the V800 to $44.4 \%(16 / 36)$ in the G5X+ (Figure 3). Overall, only the AW4 $(P=.08)$ and the $\operatorname{V800}(P=.83)$ showed no statistically significant differences from the reference distance. 
Figure 3. Relative deviation of the distances recorded by the 8 watches compared with the reference distance. The red lines indicate the proposed equivalence zone ( $\pm 5 \%$ of the mean); the boxplots' lower and upper boundaries indicate the $25 \%$ and $75 \%$ quantiles of the distance data, respectively, and the middle notch indicates the median data value. The whiskers include all data points that fall within the 1.5 interquartile range of the $25 \%$ and $75 \%$ quantile values. Circles and stars indicate distance data points that lie beyond the 1.5 and 3 interquartile ranges, respectively.

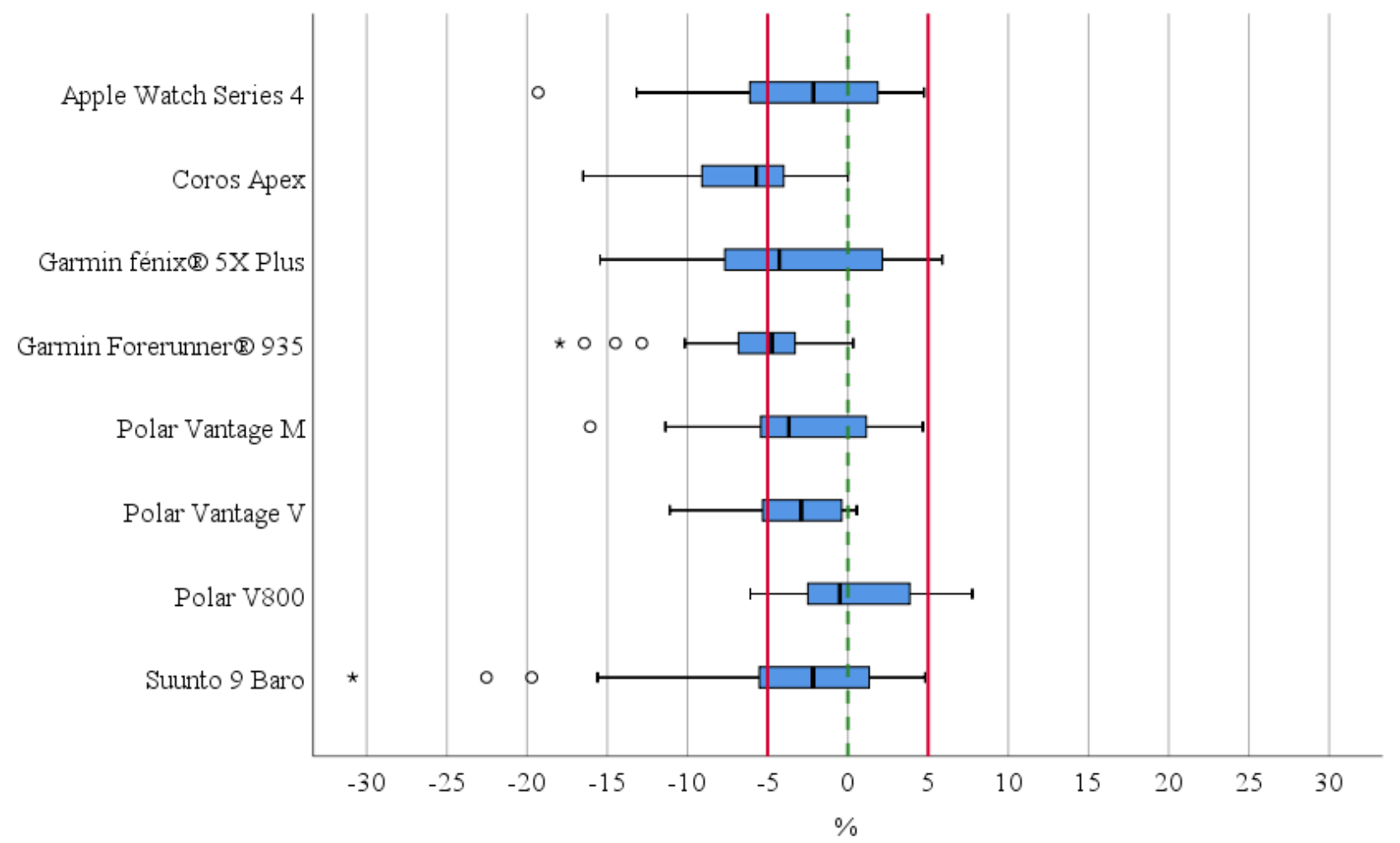

\section{Measurement Areas}

Specifically, the recorded distances were significantly different from the measured distances in the forest (all $P<.04$ ), urban (all $P<.03$ ), and track and field areas (AW4, G5X+, and S9 all $P<.001$; Tables 2-4). The Bland-Altman analyses showed an underestimation by all watches in the forest and urban areas (except the overestimation in the V800) but an overestimation in the track and field area. Further, in all watches, the lowest MAE and good $\pm 5 \%$ accuracy were recorded in the track and field measurements.

Table 2. Recorded distances and error rates of the eight sport watches obtained in the urban area when compared with the mean reference distance of $2046.4(\operatorname{SD} 1159.7) \mathrm{m}(\mathrm{n}=12)$.

\begin{tabular}{llllll}
\hline Watch & $\begin{array}{l}\text { Recorded distance }(\mathrm{m}), \\
\text { mean }(\mathrm{SD})\end{array}$ & $P$ value & $\begin{array}{l}\text { Systematic errors }(\mathrm{m}), \\
\text { (limits of agreement) }\end{array}$ & $\begin{array}{l}\text { Mean absolute error }(\mathrm{m}),(\mathrm{mean} \\
\text { absolute percentage error) }\end{array}$ & $5 \%$ accuracy, $\mathrm{n}(\%)$ \\
\hline AW4 & $1951.6(1088.3)$ & .03 & $-94.8(257.6)$ & $108.4(5.1)$ & $7(58)$ \\
CoA & $1899.5(1085.6)$ & .001 & $-146.9(237.4)$ & $146.9(7.5)$ & $4(33)$ \\
G5X+ & $1939.9(1114.9)$ & .003 & $-106.4(186.4)$ & $110.8(5.9)$ & $6(50)$ \\
GF935 & $1857.1(1054.5)$ & .003 & $-189.3(344.7)$ & $189.3(8.9)$ & $4(33)$ \\
VM & $1949.2(1110.1)$ & .02 & $-97.9(234.8)$ & $109.8(5.3)$ & $7(58)$ \\
VV & $1941.9(1118.9)$ & 0 & $-104.5(171.6)$ & $105.3(5.4)$ & $5(42)$ \\
V800 & $2134.6(1227.1)$ & .003 & $88.2(154.8)$ & $89.4(3.9)$ & $8(67)$ \\
S9B & $1868.7(1006.9)$ & .02 & $-177.7(438.7)$ & $191.6(8.5)$ & $5(42)$ \\
\hline
\end{tabular}

${ }^{\mathrm{a}}$ Percentage at which the distance recorded by each device was within $5 \%$ of the reference distance. 
Table 3. Recorded distances and error rates of the eight sport watches obtained in the forest area when compared with the mean reference distance of 2111.6 (SD 1109.9) $\mathrm{m}(\mathrm{n}=12)$.

\begin{tabular}{llllll}
\hline Watch & $\begin{array}{l}\text { Recorded distance }(\mathrm{m}), \\
\text { mean }(\mathrm{SD})\end{array}$ & $P$ value & $\begin{array}{l}\text { Systematic errors }(\mathrm{m}), \\
\text { (limits of agreement) }\end{array}$ & $\begin{array}{l}\text { Mean absolute error }(\mathrm{m}),(\mathrm{mean} \\
\text { absolute percentage error) }\end{array}$ & $5 \%$ accuracy ${ }^{\mathrm{a}}, \mathrm{n}(\%)$ \\
\hline AW4 & $1969.8(1031.9)$ & .008 & $-141.8(297.8)$ & $148.3(6.9)$ & $5(41.7)$ \\
CoA & $1944.1(1032.6)$ & $<.001$ & $-167.4(177.2)$ & $167.4(8.5)$ & $2(16.7)$ \\
G5X+ & $1946.1(1029.2)$ & $<.001$ & $-165.4(175.7)$ & $165.4(8.2)$ & $0(0.0)$ \\
GF935 & $1983.0(1037.5)$ & $<.001$ & $-128.6(171.3)$ & $128.6(6.0)$ & $4(33.3)$ \\
VM & $1993.4(1048.7)$ & $<.001$ & $-118.2(149.7)$ & $118.1(5.6)$ & $6(50.0)$ \\
VV & $2000.4(1047.4)$ & .001 & $-111.2(157.8)$ & $111.1(5.0)$ & $7(58.3)$ \\
V800 & $2030.6(1063.3)$ & .002 & $-81.0(140.3)$ & $81.0(3.5)$ & $9(75.0)$ \\
S9B & $1827.9(988.1)$ & .07 & $-166.5(529.4)$ & $166.5(7.5)$ & $6(54.5)^{\mathrm{b}}$ \\
\hline
\end{tabular}

${ }^{a}$ Percentage at which the distance recorded by each device was within $5 \%$ of the reference distance.

$\mathrm{b}_{\mathrm{n}=11}$.

Table 4. Recorded distances and error rates of the eight sport watches obtained in the track and field area when compared with the reference distance of 2104.3 (SD 1167.4) $\mathrm{m}(\mathrm{n}=12)$.

\begin{tabular}{llllll}
\hline Watch & $\begin{array}{l}\text { Recorded distance }(\mathrm{m}), \\
\text { mean (SD) }\end{array}$ & $P$ value & $\begin{array}{l}\text { Systematic errors }(\mathrm{m}), \\
\text { (limits of agreement) }\end{array}$ & $\begin{array}{l}\text { Mean absolute error }(\mathrm{m}),(\mathrm{mean} \\
\text { absolute percentage error) }\end{array}$ & $\begin{array}{l}5 \% \text { accuracy }{ }^{\mathrm{a}}, \mathrm{n}(\%) \\
\text { AW4 }\end{array}$ \\
\hline $2196.4(1227.4)$ & .001 & $92.1(137.6)$ & $92.1(4.1)$ & $18.7(0.9)$ & $12(100)$ \\
CoA & $2115.7(1180.4)$ & .13 & $11.4(47.3)$ & $61.1(3.0)$ & $10(83)$ \\
G5X+ & $2165.4(1190.1)$ & .001 & $61.1(86.7)$ & $31.2(1.3)$ & $12(100)$ \\
GF935 & $2121.6(1182.2)$ & .20 & $17.2(86.3)$ & $48.7(2.1)$ & $12(100)$ \\
VM & $2142.3(1214.5)$ & .049 & $38.0(116.8)$ & $43.8(2.3)$ & $10(83)$ \\
VV & $2134.1(1206.0)$ & .05 & $29.8(92.7)$ & $53.4(2.3)$ & $12(100)$ \\
V800 & $2108.2(1171.5)$ & .85 & $3.9(134.6)$ & $49.2(2.5)$ & $12(100)$ \\
S9B & $2150.5(1194.8)$ & .001 & $46.1(65.4)$ &
\end{tabular}

${ }^{\mathrm{a}}$ Percentage at which the distance recorded by each device was within $5 \%$ of the reference distance.

\section{Affecting Parameters}

The backward multiple linear regression analyses on each watch revealed different significant predictors of an increased MAE (Table 5). The included independent variables explained between $18.3 \%$ of the variance in the MAE in the AW4 and $44.2 \%$ in the CoA. The running category was the most shown predictor; in six watches, it remained and had a significant influence on the final regression models and explained between $<1 \%$ and $9 \%$ of the MAE in the respective watches. 
Table 5. Linear regressions for each device separately with the mean absolute error as dependent variable.

\begin{tabular}{|c|c|c|c|c|c|}
\hline Watch and predictors & Interpretation $^{\mathrm{a}}$ & Odds ratio ( $P$ value) & $R^{2}$ & $F$ value & Explained variance, $\beta^{2}(\%)$ \\
\hline AW & & & .18 & 3.71 & \\
\hline Running & Running over walking and cycling & $76.48(.05)$ & & & 8 \\
\hline Arm position & Lower forearm position & $65.10(.08)$ & & & 10 \\
\hline CoA & & & .44 & 13.08 & \\
\hline Track and field & Urban and forest over track and field & $-138.47(<.001)$ & & & 37 \\
\hline Running & Running over walking and cycling & $59.49(.05)$ & & & 7 \\
\hline G5X+ & & & .32 & 5.09 & \\
\hline Track and field & Urban and forest over track and field & $-104.34(.002)$ & & & 18 \\
\hline Running & Running over walking and cycling & $49.65(.07)$ & & & 8 \\
\hline Forest & Forest over urban & $-54.60(.08)$ & & & $<1$ \\
\hline GF935 & & & .40 & 7.14 & \\
\hline Temperature & Lower temperatures & $-14.11(.002)$ & & & 20 \\
\hline Urban & Urban over forest and track and field & $102.72(.01)$ & & & 16 \\
\hline Time of day & Later in the day & $394.14(.02)$ & & & $<1$ \\
\hline VM & & & .21 & 4.49 & \\
\hline Precipitation & More rain & $39.15(.03)$ & & & 9 \\
\hline Running & Running over walking and cycling & $62.92(.03)$ & & & 9 \\
\hline $\mathbf{V V}$ & & & .43 & 4.54 & \\
\hline Precipitation & More rain & $47.19(.003)$ & & & 12 \\
\hline Running & Running over walking and cycling & $66.99(.02)$ & & & 6 \\
\hline Solar irradiance & More solar irradiance & $.11(.05)$ & & & 4 \\
\hline Turns per $1000 \mathrm{~m}$ & More turns & $5.73(.05)$ & & & 5 \\
\hline Cycle & Cycling over walking & $48.94(.07)$ & & & 1 \\
\hline V800 & & & .39 & 6.91 & \\
\hline Precipitation & More rain & $43.53(.001)$ & & & 28 \\
\hline Cycle & Cycling over running and walking & $49.59(.03)$ & & & 8 \\
\hline Running & Running over walking & $42.39(.06)$ & & & $<1$ \\
\hline S9 & & & .27 & 3.79 & \\
\hline Temperature & Lower temperatures & $-24.25(.004)$ & & & 10 \\
\hline Humidity & Less humid & $-5.82(.02)$ & & & 2 \\
\hline Sun & More clouds & $-2.73(.08)$ & & & 1 \\
\hline
\end{tabular}

${ }^{\mathrm{a}}$ The mean absolute error was increased by the respective predictors.

\section{Discussion}

\section{Principal Findings}

The aim of this study was to evaluate the accuracy of the recorded distances of eight sport watches under different real-world environmental conditions for various speeds and reveal the predictors affecting measurement quality. Our results showed that the V800 was the most accurate watch overall, with a systematic error of $3.7 \mathrm{~m}$, a MAPE of $3.2 \%$, and $80.6 \%$ of all distance recordings within $\pm 5 \%$ of the reference values. Notably, the V800 can use only GPS satellites due to its antenna implementation. Consequently, it is questionable whether the number of satellites and combination of different GPS + GLONASS or Galileo affects measurement quality that much, which was previously questioned [1]. In contrast, other devices showed a significant systematic error of up to $-101.0 \mathrm{~m}$ and limits of agreements of over $\pm 400 \mathrm{~m}$, overall MAPEs of up to $6.1 \%$, and less than $50 \%$ of the data falling within the tolerable range of $\pm 5 \%$ (Figure 3 ). Overall, the recorded distances were underestimated in all watches, and the variance and some outliers were rather high. In contrast, during the Trollinger Half-Marathon, an overall MAPE of $0.6 \%$ was observed in the GNSS-enabled devices, of which the Garmin devices performed the most accurately [3]. In addition, the recorded distances 
generally showed an overestimation of the half-marathon distance. However, comparability with our study is limited, as our data were assessed under standardized conditions, whereas during the Trollinger Half-Marathon, all runners started/stopped and calibrated their devices individually and potentially did not run on the ideal route to complete the entire $21.1 \mathrm{~km}$.

\section{Measurement Areas}

Considering the different measurement areas separately, an underestimation of the recorded distances in the forest and urban areas (except for the V800) was observed. In these areas, the MAPEs ranged from $-3.5 \%$ to $-8.9 \%$, and a low $5 \%$ accuracy of $0 \%$ to $75 \%$ indicated large variances. This was in line with the previous research, demonstrating an underestimation of the recorded distances by $-1.2 \%$ and $-6.2 \%$ in an urban and forest area, respectively [5]. These results underline the fact that the GNSS signal is reduced in obstructed conditions such as dense vegetation or near objects and buildings, as it may reflect off before it reaches the GNSS receiver (ie, the GNSS not only receives signals directly from the satellites, signals are also reflected off such surfaces) [16]. In contrast, in the track and field area, the recorded distances were overestimated compared with the reference distance. However, the MAPEs were all $<5 \%$ and ranged from $0.9 \%$ to $4.1 \%$ only. Furthermore, a good $5 \%$ accuracy was shown in the track and field area, with 5 devices having 100\% (CoA, GF935, VM, V800, S9B), 2 devices having $83 \%(\mathrm{G} 5 \mathrm{X}+, \mathrm{VV})$, and 1 device having 67\% (AW4) of the distance recordings falling within the $\pm 5 \%$ accuracy threshold. The authors assume that manufacturers may autocorrect the recorded distances in the first place to level out the underestimation in difficult areas, which may in turn result in an overestimation of the distance recordings in unobstructed conditions, such as flat and open areas [17].

\section{Affecting Parameters}

The included independent variables explained as much as from $18.3 \%$ to $44.2 \%$ of the variance in the MAEs of the distance recordings. Additionally, the running category showed in $75 \%$ $(6 / 8)$ of the sport watches significantly increased error rates in recorded distances when compared with walking and cycling speeds. We assume this error is related to the gait-induced arm swing than to the movement speed itself. In comparison, cycling was the activity with the highest absolute speed, but in $25 \%$ $(2 / 8)$ of the watches, it remained in the final regression model only. Previously, research compared the recorded altitude gains when assessed in the same brand on sport watches simultaneously placed on the wrist and on the hip when walking or running [26]. The watch placed on the hip was always more accurate than the watch placed on the wrist, and the error in altitude measures increased with faster movement speed. It was argued that the gait-related arm swing negatively affected the measurement accuracy which, in running, is raised in amplitude and frequency compared with walking. Furthermore, in our study, more rain was a significant predictor of an increased MAE in $38 \%(3 / 8)$ of the watches, which might be related to the impaired measurement accuracy in cloudy weather.

\section{Practical Implications}

Recent research highlighted the broad use of GNSS-enabled watches in runners of different fitness levels and that users trust the data of such devices [3,4]. However, our study showed, depending on what device was applied, that from $80.6 \%$ (29/36) to as little as $44.4 \%(16 / 36)$ of the mean recorded distances fell within $\pm 5 \%$ when compared with the reference values. In particular, running over walking and cycling activities were shown to impair the GNSS accuracy in the recorded distances. Nevertheless, the use of all the investigated sport watches can be recommended, especially for distance recordings in an open area. Yet in case of training monitoring and regulation based on recorded distance data, one must be aware that the recorded distances might be underestimated by up to $9 \%$. As such, correct execution of the manufacturers' instructions is essential to get the best accuracy (ie, for the latest satellite data to be valid).

\section{Limitations}

Although we controlled for the wearing side and wearing position of the sport watches, we cannot exclude potential interference between the devices [10]. Only 14\% (5/36) of the measurements were accomplished with moderate to heavy precipitation. In addition, the independent variables watch-wearing side and watch-wearing position occurred in a limited number of measurements only. Therefore, the power in the regression analysis is reduced, which in turn diminishes the interpretation of these predictors of increased error rates. Our data acquisition was performed by a single subject to ascertain perfect standardization. However, we cannot exclude that a study sample with different anthropometrics would fully affirm our results. Last, the selection of the specific eight sport watches might be biased as it was based on personal communications with exercise physiologists and endurance athletes rather than based on a detailed market research.

\section{Conclusions}

Our results showed that there was an overall moderate to good GNSS accuracy regarding recorded distances, with MAPEs ranging from $3.2 \%$ to $6.1 \%$ when assessed in urban, forest, and track and field areas. However, only three of the eight investigated GNSS-enabled sport watches reported an average MAPE $<5 \%$. Noticeably, in the unobstructed conditions of an open area, $75 \%(6 / 8)$ of the sport watches were able to accurately record distances, whereas in the obstructed conditions of forest and urban areas, this accuracy was limited, with a general underestimation of the covered distances. Furthermore, the data assessed during running showed significantly higher error rates in most devices compared with the walking and cycling activities.

\section{Acknowledgments}

Polar Electro Oy (Finland) funded this experiment in part. Polar Electro Oy provided the Swiss Federal Institute of Sport Magglingen (SFISM) with financial support to conduct the study. The funding was targeted for data collection, results analysis, and Polar reporting costs. Additionally, the products tested were provided by Polar. The Polar products were from the company stock directly and the other products were bought by Polar from stores and given to us for the period of the study. After termination, 
all products were returned to Polar. As agreed beforehand, representatives from Polar Electro Oy had no influence on the data collection or analysis or on the outcome of the article or any right to stop the SFISM from publishing the findings. The manuscript content does not necessarily reflect the views of Polar Electro Oy.

\section{Authors' Contributions}

RGA and TW conceived and designed the research. TS conducted the experiments. RGA analyzed the data and wrote the manuscript. All the authors read and approved the manuscript.

\section{Conflicts of Interest}

None declared.

\section{Multimedia Appendix 1}

Bland-Altman plots for each device distinguished by measurement areas and speed categories.

[PNG File, $261 \mathrm{~KB}-$ Multimedia Appendix 1]

\section{References}

1. Malone JJ, Lovell R, Varley MC, Coutts AJ. Unpacking the black box: applications and considerations for using GPS devices in sport. Int J Sports Physiol Perform 2017 Apr;12(Suppl 2):S218-S226. [doi: 10.1123/ijspp.2016-0236] [Medline: 27736244]

2. Thompson WR. Worldwide survey of fitness trends for 2019. ACSM Health Fitness J 2018;22(6):10-17. [doi: 10.1249/fit.0000000000000438]

3. Pobiruchin M, Suleder J, Zowalla M, Wiesner M. Accuracy and adoption of wearable technology used by active citizens: a marathon event field study. JMIR Mhealth Uhealth 2017 Mar 28;5(2):e24 [FREE Full text] [doi: 10.2196/mhealth.6395] [Medline: 28246070]

4. Wiesner M, Zowalla R, Suleder J, Westers M, Pobiruchin M. Technology adoption, motivational aspects, and privacy concerns of wearables in the German running community: field study. JMIR Mhealth Uhealth 2018 Dec 14;6(12):e201 [FREE Full text] [doi: 10.2196/mhealth.9623] [Medline: 30552085]

5. Nielsen RO, Cederholm P, Buist I, Sørensen H, Lind M, Rasmussen S. Can GPS be used to detect deleterious progression in training volume among runners? J Strength Conditioning Res 2013;27(6):1471-1478. [doi: 10.1519/jsc.0b013e3182711e3c]

6. Silva A, Simões P, Queirós A, Rodrigues M, Rocha NP. Mobile apps to quantify aspects of physical activity: a systematic review on its reliability and validity. J Med Syst 2020 Jan 08;44(2):51. [doi: 10.1007/s10916-019-1506-z] [Medline: 31915935]

7. Evenson KR, Goto MM, Furberg RD. Systematic review of the validity and reliability of consumer-wearable activity trackers. Int J Behav Nutr Phys Act 2015;12(1):159 [FREE Full text] [doi: 10.1186/s 12966-015-0314-1] [Medline: 26684758]

8. Bauer C. On the (in-)accuracy of GPS measures of smartphones: a study of running tracking applications. 2013 Presented at: 11th International Conference on Advances in Mobile Computing \& Multimedia; 2013; Vienna p. 335-341. [doi: $10.1145 / 2536853.2536893]$

9. Schipperijn J, Kerr J, Duncan S, Madsen T, Klinker J, Troelsen J. Dynamic accuracy of GPS receivers for use in health research: a novel method to assess GPS accuracy in real-world settings. Front Public Health 2014;2:21 [FREE Full text] [doi: 10.3389/fpubh.2014.00021] [Medline: 24653984]

10. Düking P, Fuss FK, Holmberg H, Sperlich B. Recommendations for assessment of the reliability, sensitivity, and validity of data provided by wearable sensors designed for monitoring physical activity. JMIR Mhealth Uhealth 2018 Apr 30;6(4):e102 [FREE Full text] [doi: 10.2196/mhealth.9341] [Medline: 29712629]

11. GPS constellation status. URL: https://navcen.uscg.gov/?Do=constellationStatus [accessed 2020-05-30]

12. GLONASS constellation status. URL: https://www.glonass-iac.ru/en/GLONASS/index.php [accessed 2020-05-30]

13. Constellation information. URL: https://www.gsc-europa.eu/system-service-status/constellation-information [accessed 2020-05-30]

14. Systems: the development path. URL: http://en.beidou.gov.cn/SYSTEMS/System/ [accessed 2020-05-30]

15. Larsson P. Global positioning system and sport-specific testing. Sports Med 2003;33(15):1093-1101. [doi: 10.2165/00007256-200333150-00002] [Medline: 14719979]

16. Duncan S, Stewart TI, Oliver M, Mavoa S, MacRae D, Badland HM, et al. Portable global positioning system receivers: static validity and environmental conditions. Am J Prev Med 2013 Feb;44(2):e19-e29. [doi: 10.1016/j.amepre.2012.10.013] [Medline: 23332343]

17. Ranacher P, Brunauer R, Trutschnig W, Van der Spek S, Reich S. Why GPS makes distances bigger than they are. Int J Geogr Inf Sci 2016 Mar 01;30(2):316-333 [FREE Full text] [doi: 10.1080/13658816.2015.1086924] [Medline: 27019610]

18. Precision of GPS navigation definitions. URL: http://www.sdcm.ru/smglo/st gps?version=eng\&repdate\&site=extern [accessed 2019-11-27] 
19. Precision of GLONASS navigation definitions. URL: http://www.sdcm.ru/smglo/st_glo?version=eng\&repdate\&site=extern [accessed 2019-11-27]

20. Precision of GLONASS/GPS navigation definitions. URL: http://www.sdcm.ru/smglo/ stparam?version=eng\&repdate\&site=extern [accessed 2019-11-27]

21. Scott MT, Scott TJ, Kelly VG. The validity and reliability of global positioning systems in team sport: a brief review. J Strength Cond Res 2016 May;30(5):1470-1490. [doi: 10.1519/JSC.0000000000001221] [Medline: 26439776]

22. Nedo Leichtmessrad Professional. URL: http://www.nedo.ch/index.pl?Lang=fimex\&Page=products/vmg/messraeder.html [accessed 2019-11-11]

23. E-Stream Eva TR. URL: https://www.bulls.de/produkt/bulls-e-streamevatr2275-727-52041 [accessed 2019-11-11]

24. Suresh K. An overview of randomization techniques: an unbiased assessment of outcome in clinical research. J Hum Reprod Sci 2011 Jan;4(1):8-11 [FREE Full text] [doi: 10.4103/0974-1208.82352] [Medline: 21772732]

25. Shcherbina A, Mattsson CM, Waggott D, Salisbury H, Christle JW, Hastie T, et al. Accuracy in wrist-worn, sensor-based measurements of heart rate and energy expenditure in a diverse cohort. J Pers Med 2017 May 24;7(2) [FREE Full text] [doi: 10.3390/jpm7020003] [Medline: 28538708]

26. Ammann R, Taube W, Neuhaus M, Wyss T. The influence of the gait-related arm swing on elevation gain measured by sport watches. J Hum Kinet 2016 Jun 01;51:53-60 [FREE Full text] [doi: 10.1515/hukin-2015-0170] [Medline: 28149368]

\author{
Abbreviations \\ AW4: Apple Watch Series 4 (Apple Inc) \\ CoA: Apex $46 \mathrm{~mm}$ (Coros Wearables Inc) \\ G5X+: Fenix 5X Plus (Garmin Ltd) \\ GF935: Forerunner 935 (Garmin Ltd) \\ GLONASS: Global Navigation Satellite System \\ GNSS: global navigation satellite system \\ MAE: mean absolute error \\ MAPE: mean absolute percentage error \\ S9B: Suunto 9 Baro (Suunto Oy) \\ V800: V800 (Polar Electro Oy) \\ VM: Vantage M (Polar Electro Oy) \\ VV: Vantage V (Polar Electro Oy)
}

Edited by G Eysenbach; submitted 10.12.19; peer-reviewed by M Pobiruchin, M Wiesner; comments to author 27.01.20; revised version received 21.03.20; accepted 19.04.20; published 24.06.20

Please cite as:

Gilgen-Ammann R, Schweizer T, Wyss T

Accuracy of Distance Recordings in Eight Positioning-Enabled Sport Watches: Instrument Validation Study

JMIR Mhealth Uhealth 2020;8(6):e17118

URL: http://mhealth.jmir.org/2020/6/e17118/

doi: $10.2196 / 17118$

PMID: 32396865

CRahel Gilgen-Ammann, Theresa Schweizer, Thomas Wyss. Originally published in JMIR mHealth and uHealth (http://mhealth.jmir.org), 24.06.2020. This is an open-access article distributed under the terms of the Creative Commons Attribution License (https://creativecommons.org/licenses/by/4.0/), which permits unrestricted use, distribution, and reproduction in any medium, provided the original work, first published in JMIR mHealth and uHealth, is properly cited. The complete bibliographic information, a link to the original publication on http://mhealth.jmir.org/, as well as this copyright and license information must be included. 